\title{
Effects of consuming alcohol mixed with energy drinks versus consuming alcohol only on overall alcohol consumption and negative alcohol-related consequences
}

\author{
This article was published in the following Dove Press journal: \\ International Journal of General Medicine \\ 14 November 2012 \\ Number of times this article has been viewed
}

\section{Lydia de Haan' \\ Hein A de Haan ${ }^{2,3}$ \\ Job van der Palen ${ }^{4,5}$ \\ Berend Olivier' \\ Joris C Verster'}

'Utrecht University, Utrecht Institute for Pharmaceutical Sciences, Division of Pharmacology, Utrecht, ${ }^{2}$ Tactus Addiction Treatment, Deventer, ${ }^{3}$ Nijmegen Institute for Scientist-Practitioners in Addiction, Nijmegen, ${ }^{4}$ Medical School Twente, Medisch Spectrum Twente, Enschede, ${ }^{5}$ Department of Research Methodology, Measurement, and Data Analysis, University of Twente, Enschede, The Netherlands
Correspondence: Joris CVerster Utrecht University, Utrecht Institute for Pharmaceutical Sciences, Division of Pharmacology, Universiteitsweg 99, CG3584, Utrecht, The Netherlands Tel +31302536909

Email j.c.verster@uu.nl
Background: The aim of this study was to examine differences in alcohol consumption and its consequences when consumed alone and when mixed with energy drinks.

Methods: A survey was conducted among Dutch students at Utrecht University and the College of Utrecht. We collected data on alcohol consumption and alcohol-related consequences of alcohol consumed alone and/or alcohol mixed with energy drinks (AMED). The data were analyzed using a retrospective within-subject design, comparing occasions when subjects consumed AMED with those when they consumed alcohol only in the past 30 days.

Results: A representative sample of 6002 students completed the survey, including 1239 who consumed AMED. Compared with consuming alcohol only, when consuming AMED, students consumed significantly fewer alcoholic drinks on an average drinking day (6.0 versus 5.4, respectively), and reported significantly fewer drinking days in the previous month (9.2 versus 1.4 ), significantly fewer days being drunk (1.9 versus 0.5$)$, and significantly fewer occasions of consuming more than four (female)/five (male) alcoholic drinks (4.7 versus 0.9). The maximum number of mixed alcoholic drinks (4.5) in the previous month was significantly lower when compared with occasions when they consumed alcohol only (10.7). Accordingly, the mean duration of a drinking session was significantly shorter when mixing alcoholic drinks (4.0 versus 6.0 hours). Finally, when consuming AMED, significantly fewer alcohol-related consequences were reported (2.6) for the previous year, including driving a car while intoxicated, taking foolish risks, or being injured or hurt, as compared with alcohol-related consequences when consuming alcohol only (4.9).

Conclusion: Mixing alcohol with energy drinks decreases overall alcohol consumption, and decreases the likelihood of experiencing negative alcohol-related consequences.

Keywords: alcohol, energy drinks, AMED, alcohol consumption, consequences

\section{Introduction}

Alcohol abuse is a major problem worldwide. It has been estimated that $42 \%$ of males and $20 \%$ of females in the US will experience an alcohol use disorder (abuse or dependence) during their lifetime, and approximately $12.5 \%$ of males and $5 \%$ of females meet the criteria for an alcohol use disorder in the previous year. ${ }^{1}$ Excessive alcohol consumption is ranked as the third leading cause of death in the US, and is also associated with marked functional impairment. ${ }^{1-3}$ According to the World Health Organization, $6.2 \%$ of all deaths worldwide are related to alcohol consumption, which makes it one of the leading causes of death. ${ }^{4}$ There is global concern about drinking 
trends among young people, particularly with regard to heavy episodic or "binge" drinking. ${ }^{5}$ For example, in the US, about 500,000 college students are injured every year due to drinking alcohol, with about 1700 of them dying annually due to extreme binge-drinking. ${ }^{6}$ During adolescence, several neural systems undergo alterations, and during maturation, some of these systems modulate sensitivity to a variety of the effects of alcohol, potentially increasing the propensity for relatively high levels of adolescent alcohol use. This might set the stage for later alcohol use disorders. ${ }^{7}$ Hence, it is important to study factors that may contribute to increased alcohol consumption among young adults.

Concerns have been raised regarding the potential negative consequences of consumption of alcohol mixed with energy drinks (AMED). The relevant ingredient in this context is caffeine, of which most popular energy drinks contain $80 \mathrm{mg}$ per $250 \mathrm{~mL}$ or $8.4 \mathrm{fl} \mathrm{oz} .{ }^{8,9}$ The stimulant effect of caffeine is thought to counteract the sedative effect of alcohol, possibly leading to increased alcohol consumption and experiencing of more negative alcohol-related consequences. Only a few studies have investigated whether use of AMED is indeed associated with more alcohol consumption. O'Brien et al questioned 4271 college students, of whom 52\% had consumed alcohol without mixing with energy drinks and $16.3 \%$ $(\mathrm{N}=697$ ) had consumed AMED in the previous 30 days, and concluded the AMED consumers to be at increased risk for alcohol-related consequences, even when adjusted for the amount of alcohol consumed. ${ }^{10}$ This conclusion was based on a between-subjects comparison of AMED consumers and alcohol-only consumers. A similar design was used by Arria et al, comparing college students who consumed energy drinks versus those who did not consume energy drinks in a 3-year longitudinal study. It was concluded that consumers of energy drinks tend to have a greater involvement in alcohol and drug use and have higher levels of sensation-seeking, compared with students who do not consume energy drinks. ${ }^{11}$ Other surveys reported similar significant correlations between energy drink and alcohol consumption, and reported that those who consume AMED generally consume more alcohol and experience more alcohol-related consequences than those who consume alcohol alone. ${ }^{12-15}$

These conclusions have raised concerns regarding AMED consumption. However, some researchers have questioned the methodology of these surveys and the interpretation of the results regarding designs used to research AMED consumption, ${ }^{8,16,17}$ and two studies did not find comparable results while using a between-groups design. ${ }^{18,19}$ Penning et al reported that those who consume AMED do not consume more alcohol than those who consume alcohol only. Rossheim and Thombs found no significant relationship between AMED consumption and the chances of being intoxicated (ie, having a blood alcohol content $>0.08 \%$ ). However, the main reason for criticism of existing surveys is that the majority of them have compared AMED consumers with those who consume alcohol only, using a betweengroups design. Unfortunately, by comparing an AMED group with an alcohol-only group, it is not possible to determine if there is any causal relationship between energy drink consumption and overall alcohol consumption. In other words, it cannot be established from a between-group comparison whether mixing alcohol with energy drinks had any influence on overall alcohol consumption. Also, between-group analyses introduce the influence of potential confounders, such as differences between groups regarding personality characteristics. To verify whether mixing alcohol with energy drinks increases overall alcohol consumption, studies using a within-subject design are needed. A within-subject comparison is essential to determine whether AMED groups consume more alcohol on occasions when they consume AMED compared with occasions when they consume alcohol only. Another important advantage of a within-subject design is that if a sufficient sample size is obtained, the actual response rate to the survey is of minor concern. As long as the sample that completed the survey reflects the basic demographics and characteristics of the general population, a large enough sample size with adequate power for the statistical analyses is sufficient to yield reliable research results. Nevertheless, it remains important to compare the demographic characteristics of the sample with those of the total population to ensure that the sample studied is representative of this population.

Two studies have reported the results of a within-subject comparison. ${ }^{20,21}$ Price et al found that AMED consumption was associated with increased alcohol consumption, but their sample size of 10 subjects was too small to draw conclusions. A second within-subject comparison was presented by Woolsey et al. These authors only drew conclusions based on their between-group comparison (AMED versus alcohol-only groups), but together with the within-subject comparison (ie, within the AMED group) presented, important results were revealed, supporting the hypotheses that AMED and alcohol-only groups differ from each other in critical characteristics (eg, alcohol consumption when not mixing with energy drinks), and that within the AMED group, mixing alcohol with energy drinks does not increase overall alcohol consumption when compared with occasions on which they consume alcohol only. Woolsey et al found that 
when mixing energy drinks with alcohol, AMED consumers drink significantly less alcohol than on occasions when they consume alcohol only (6.28 drinks versus 8.60 drinks, respectively). Because the within-subject comparison by Woolsey et al was performed in a relatively small sample of AMED consumers $(n=150)$, surveys with a larger sample size are needed to confirm these findings. Given the limitations of previous survey research on mixing energy drinks with alcohol, an extensive online survey was developed and conducted in The Netherlands. The aim of this survey was to examine alcohol consumption and its consequences when consumed alone or when mixed with energy drinks using a within-subject design. Given the current scientific evidence available, it was hypothesized that there is no difference in total alcohol consumption (frequency and quantity) and alcohol-related negative consequences when alcohol is consumed alone or when mixed with energy drinks.

\section{Materials and methods Sample}

All 70,000 students from the Utrecht University and the College of Utrecht were invited by email to complete an online survey on consumption of energy drinks and alcohol. Two teams approached students at the campuses, and distributed leaflets to remind them to complete the survey. The study protocol was reviewed by the Twente medical ethics committee, but no formal medical ethics approval needed to be obtained. Participation was anonymous and voluntary, and a prize draw was held among those who completed the survey. In total, 7158 students opened the link to the survey. After cleaning the data set the final dataset comprised 6002 students. For the analyses in this paper, data were used for the alcohol-only group (ie, those who only consumed alcohol, $\mathrm{n}=3185$ ), and the AMED-group (consisting of participants who consumed both alcohol only and AMED, $\mathrm{n}=1239$ ). Data concerning the group that consume both alcohol and energy drinks but never mix these and the group that do not consume alcohol will be discussed elsewhere.

\section{Survey outline}

After obtaining demographic data from the participants, questions were asked about alcohol use when consumed alone and when mixed with energy drinks. The consumption questions were standard ones investigating the subject's consumption habits (frequency and quantity) considering the particular drink asked about, with a focus on the past 30 days, and adapted from the Quick Drinking Screen, which contains four consumption questions that have been shown to be highly reliable and consistent when compared with the 12-month Timeline Follow Back method. ${ }^{22,23}$ Mixing was defined as consuming energy drinks within a time frame of 2 hours before or after drinking alcohol.

The Dutch version of the Brief Young Adult Alcohol Consequences Questionnaire (BYAACQ) was included to study alcohol-related negative consequences. ${ }^{24}$ The BYAACQ consists of 24 possible consequences of alcohol consumption that can be answered by "yes" or "no". The outcome score ranges from 0 to 24 . The BYAACQ was completed for alcohol only and for mixing with energy drinks depending on the specific drinking behavior of the participant. In addition to the BYAACQ, two additional items were included to determine whether participants were injured or got into a fight after alcohol consumption (with or without mixing with energy drinks). A detailed description of the survey design and its questions can be found elsewhere. ${ }^{25}$ Furthermore, it should be taken into account that alcoholic drinks in The Netherlands, when obtained in a bar, pub, or restaurant, contain a standardized amount of alcohol.

\section{Data collection and statistical analyses}

The survey went online on June 6, 2011 and remained online for 10 days. Data were collected online via SurveyMonkey and analyzed using the Statistical Package for the Social Sciences version 18 (SPSS Inc, Chicago, IL). The mean, standard deviation, and frequency distribution was computed for alcohol consumption questions and BYAACQ scores for occasions on which subjects consumed AMED or alcohol only. Variables with a normal distribution were tested with the Student $t$-test. For nominal variables, a $\chi^{2}$-test was performed. To analyze within-subject differences within the AMED group (drinking AMED versus drinking alcohol only), a paired $t$-test was used for consumption questions, and intraclass correlations were calculated to look for interindividual correlations where appropriate. For the BYAACQ data, a McNemar test was performed on the single items, and a paired $t$-test and intraclass correlation on the BYAACQ total scores. All tests were two-tailed, and differences were regarded as significant at $P<0.05$.

\section{Results}

\section{Between-group comparisons}

The demographics of the participants are summarized in Table 1. The age and gender distribution of the sample obtained did not differ significantly from the total Utrecht student population. ${ }^{25}$ The alcohol-only group comprised 3185 subjects and the AMED group comprised 1239 subjects. 
Table I Demographics of study participants

\begin{tabular}{|c|c|c|c|}
\hline & $\begin{array}{l}\text { Alcohol-only group } \\
(n=3 \mid 85)\end{array}$ & $\begin{array}{l}\text { Alcohol mixed with energy } \\
\text { drinks group }(n=\mid 239)\end{array}$ & $P$ value \\
\hline Male/female ratio & $32.5 \% / 67.5 \%$ & $39.1 \% / 60.9 \%$ & $<0.001$ \\
\hline Age (years), mean (SD) & $22.1(2.6)$ & $21.5(2.3)$ & $<0.001$ \\
\hline Weight (kg), mean (SD) & $68.9(11.8)$ & $70.4(12.3)$ & $<0.001$ \\
\hline Height $(m)$, mean $(S D)$ & $\mathrm{I} .75(0.1)$ & $\mathrm{I} .76(0.1)$ & $<0.001$ \\
\hline Sorority/fraternity member & $20.6 \%$ & $22.8 \%$ & 0.113 \\
\hline Medication use & $23.2 \%$ & $23.0 \%$ & 0.905 \\
\hline Drug use & $22.0 \%$ & $38.3 \%$ & $<0.001$ \\
\hline Tobacco use & $23.2 \%$ & $41.7 \%$ & $<0.001$ \\
\hline
\end{tabular}

Abbreviation: SD, standard deviation.

Between-group analyses showed that the groups differed significantly from each other on variables related to alcoholonly consumption, smoking, and drug use, as summarized in Tables 1 and 2. Between-group analyses also revealed a consistent pattern of significant differences on most variables, in that AMED consumption was greater than alcohol-only consumption, as summarized in Table 2.

\section{Within-subject analyses for AMED group}

To establish whether mixing energy drinks with alcohol has an impact on total alcohol consumption, withinsubject comparisons were performed for members of the AMED group ( $n=1239)$, comparing occasions on which they consumed AMED with occasions on which they consumed alcohol only. The results of these comparisons are summarized in Figure 1. Intraclass correlations were calculated when appropriate to examine these within-subject comparisons further.
The within-subject analyses revealed generally lower consumption of alcohol when combining alcohol with energy drinks. Compared with consuming alcohol only, when consuming AMED, students consumed significantly fewer alcoholic drinks (mean $6.0 \pm 3.9$ versus $5.4 \pm 3.7$, respectively; intraclass correlation $0.636, P \leq 0.001$ ) during an average drinking session, and reported significantly fewer drinking days in the previous month $(9.2 \pm 6.4$ versus $1.4 \pm 1.8)$, significantly fewer days being drunk $(1.9 \pm 2.7$ versus $0.5 \pm 1.0$ ), and significantly fewer occasions of consuming more than four (female)/five (male) alcoholic drinks ( $4.7 \pm 4.7$ versus $0.9 \pm 1.7)$. Furthermore, compared with consuming alcohol only, when consuming AMED, students consumed significantly fewer maximum number of alcoholic drinks on a single occasion in the previous month $(10.7 \pm 6.8$ versus $4.5 \pm 5.7$, respectively; intraclass correlation $0.185, P \leq 0.001$ ). Accordingly, duration of alcohol consumption on this occasion was significantly shorter

Table 2 Between-group comparison of those who consumed alcohol only and those who mixed alcohol with energy drinks with regard to their alcohol consumption on occasions when they consume alcohol only (without mixing with energy drinks)

\begin{tabular}{|c|c|c|c|}
\hline & $\begin{array}{l}\text { Alcohol-only group } \\
(\mathrm{n}=3185)\end{array}$ & $\begin{array}{l}\text { Alcohol mixed with } \\
\text { energy drinks group } \\
(n=1239)\end{array}$ & $P$ value \\
\hline At what age did you first consume alcohol? & $14.5(2.0)$ & $14.0(1.9)$ & $<0.001$ \\
\hline At what age did you consume alcohol regularly? & $17.2(1.9)$ & $16.5(1.7)$ & $<0.001$ \\
\hline How many standard drinks do you usually have on one occasion? & $4.1(3.1)$ & $6.0(3.9)$ & $<0.001$ \\
\hline In the past 30 days, how many days did you drink alcohol? & $7.9(6.3)$ & $9.2(6.4)$ & $<0.001$ \\
\hline In the past 30 days, how many days did you get drunk? & $1.0(1.9)$ & $1.9(2.7)$ & $<0.001$ \\
\hline $\begin{array}{l}\text { In the past } 30 \text { days, how many times did you have more than } \\
\text { five (male)/four (female) alcoholic drinks on one occasion? }\end{array}$ & $2.9(3.9)$ & $4.8(4.8)$ & $<0.001$ \\
\hline $\begin{array}{l}\text { In the past } 30 \text { days, what is the greatest number of alcoholic drinks } \\
\text { you had on one occasion? }\end{array}$ & $7.7(6.0)$ & $10.7(6.7)$ & $<0.001$ \\
\hline $\begin{array}{l}\text { On that occasion (previous question), how many hours did you } \\
\text { consume alcohol? }\end{array}$ & $5.1(3.1)$ & $6.0(3.1)$ & $<0.001$ \\
\hline $\begin{array}{l}\text { In the past } 12 \text { months, what was the greatest number of alcoholic drinks } \\
\text { you consumed on one occasion? }\end{array}$ & $10.7(7.1)$ & $14.6(7.9)$ & $<0.001$ \\
\hline Total BYAACQ score for drinking alcohol only & $3.1(3.0)$ & 4.9 (3.8) & $<0.001$ \\
\hline
\end{tabular}

Abbreviation: BYAACQ, Brief Young Adult Alcohol Consequences Questionnaire. 


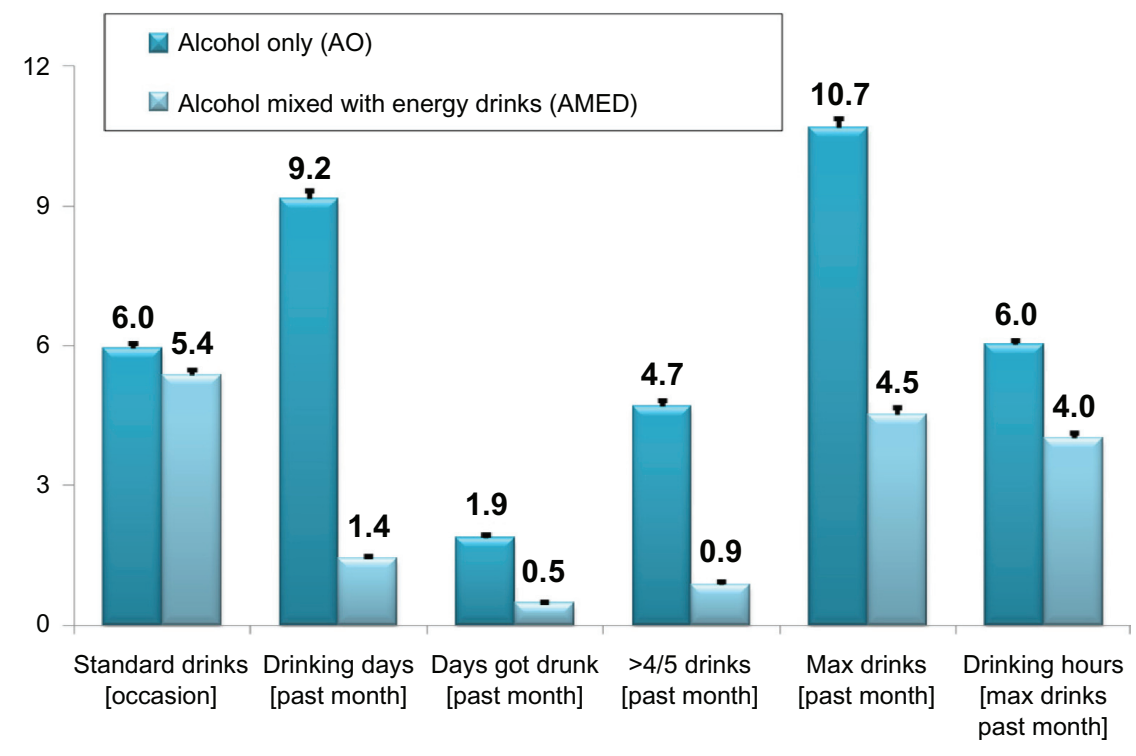

Figure I Means (SEM) for within-subjects analyses in the AMED group $(\mathrm{n}=1 \mathrm{I} 89)$ on consumption questions for alcohol only and alcohol mixed with energy drinks. Notes: Questions are specifically asked for both conditions (consuming solely alcohol/consuming alcohol mixed with energy drinks). All differences are significant at the $P<0.00$ I level.

Abbreviations: AMED, alcohol mixed with energy drinks; SEM, standard errors of the mean.

when consuming AMED than when consuming alcohol only $(4.0 \pm 3.3$ versus $6.0 \pm 3.0$ hours, respectively; intraclass correlation $0.301, P \leq 0.001$ ). All differences between consuming AMED and alcohol only were examined using a paired $t$-test and are significant at the $P<0.001$ level. Finally, the highest number of AMED consumptions on one occasion during the previous year was $4.8 \pm 4.8$.

\section{BYAACQ}

Confirmation of alcohol-related consequences after consuming AMED or alcohol only are summarized in Table 3. The within-subject comparisons show that when consuming AMED alcohol-related negative consequences are often experienced significantly less when compared with consuming alcohol only. The total BYAACQ score shows a reduction of $47 \%$ from $4.9 \pm 3.8$ for drinking alcohol only to $2.6 \pm 3.5$ for AMED (intraclass correlation $0.414, P \leq 0.001$ ). For two items (numbers 18 and 22) no significant difference was found between the AMED and alcohol only occasions. None of the individual items showed an increased chance of experiencing an alcohol-related negative consequence on AMED occasions compared with drinking alcohol only.

\section{Discussion}

The results of this survey show that people who mix alcohol with energy drinks do not consume more alcohol when they consume AMED compared with occasions on which they consume alcohol only. In contrast, when consuming AMED, students reported consuming significantly fewer alcoholic drinks on average, having fewer drinking days in the past month, less days of being drunk in the past month, and fewer occasions of consuming more than 4-5 drinks in the past month, compared with consuming alcohol only. Further, when consuming AMED, the maximum number of alcoholic drinks on one occasion during the past month was significantly lower when compared with occasions on which only alcohol was consumed. In addition, no increase in alcoholrelated consequences was reported for occasions when they consumed AMED; this finding is of importance, considering that some authors have suggested otherwise. ${ }^{10-12,14}$ The current study shows clearly that mixing alcohol with energy drinks does not increase the likelihood of potentially dangerous activities or serious negative consequences, such as driving while intoxicated, being injured, or getting involved in a fight, unplanned sexual activity, or taking foolish risks. The within-subject analyses yield results that are comparable with those reported by Woolsey et al, ${ }^{20}$ and our current results also clearly show that mixing alcohol with energy drinks does not increase overall alcohol consumption, nor the likelihood of experiencing negative consequences. The large sample size and robust findings of the current study are supportive of this conclusion.

The fact that mixing alcohol with energy drinks has no negative impact on overall alcohol consumption or its negative consequences should not be interpreted as suggesting that alcohol abuse does not exist among Dutch students. 
Table 3 Within-subjects comparison in the AMED group $(\mathrm{N}=1 \mathrm{II})$ ) on BYAACQ items for occasions on which they consumed alcohol only compared with occasions on which they mixed alcohol with energy drinks

\begin{tabular}{|c|c|c|c|c|}
\hline \multirow[t]{2}{*}{ Item } & \multirow[t]{2}{*}{ BYAACQ } & \multicolumn{2}{|c|}{ Within subject comparison } & \multirow[t]{2}{*}{$P$ value } \\
\hline & & Alcohol-only & $\begin{array}{l}\text { Alcohol mixed } \\
\text { with energy drinks }\end{array}$ & \\
\hline $\mathrm{I}$ & $\begin{array}{l}\text { I have had a hangover (headache, sick stomach) the morning } \\
\text { after I had been drinking }\end{array}$ & $861(77.6 \%)$ & $522(47.0 \%)$ & $<0.001$ \\
\hline 5 & I have had less energy or felt tired because of my drinking & $697(62.8 \%)$ & $330(29.7 \%)$ & $<0.001$ \\
\hline 10 & I have felt very sick to my stomach or thrown up after drinking & $412(37.1 \%)$ & $220(19.8 \%)$ & $<0.001$ \\
\hline 3 & $\begin{array}{l}\text { I've not been able to remember large stretches of time } \\
\text { while drinking heavily }\end{array}$ & $393(35.4 \%)$ & $198(17.8 \%)$ & $<0.001$ \\
\hline 9 & While drinking, I have said or done embarrassing things & $386(34.8 \%)$ & $193(17.4 \%)$ & $<0.001$ \\
\hline 7 & $\begin{array}{l}\text { I often have ended up drinking on nights when I had } \\
\text { planned not to drink }\end{array}$ & $308(27.7 \%)$ & $114(10.3 \%)$ & $<0.001$ \\
\hline 2 & I have taken foolish risks when I have been drinking & $300(27.0 \%)$ & $169(15.2 \%)$ & $<0.001$ \\
\hline 11 & $\begin{array}{l}\text { I have not gone to work or missed classes at school because } \\
\text { of drinking, a hangover, or illness caused by drinking }\end{array}$ & $268(24.1 \%)$ & $138(12.4 \%)$ & $<0.001$ \\
\hline 4 & $\begin{array}{l}\text { The quality of my work or school work has suffered } \\
\text { because of my drinking }\end{array}$ & $252(22.7 \%)$ & $117(10.5 \%)$ & $<0.001$ \\
\hline 12 & When drinking, I have done impulsive things I regretted later & $219(19.7 \%)$ & $114(10.3 \%)$ & $<0.001$ \\
\hline 24 & $\begin{array}{l}\text { I have found that I needed larger amounts of alcohol to feel any effect, } \\
\text { or that I could no longer get high or drunk on the amount that used to } \\
\text { get me high or drunk }\end{array}$ & $182(16.4 \%)$ & $122(\mid 1.0 \%)$ & $<0.001$ \\
\hline 16 & I have felt badly about myself because of my drinking & $155(\mid 4.0 \%)$ & $82(7.4 \%)$ & $<0.001$ \\
\hline 6 & My drinking has got me into sexual situations I later regretted & $152(13.7 \%)$ & $68(6.1 \%)$ & $<0.001$ \\
\hline 13 & I have been overweight because of drinking & $15 \mid(\mid 3.6 \%)$ & $77(6.9 \%)$ & $<0.001$ \\
\hline 15 & I have spent too much time drinking & $12 \mid(10.9 \%)$ & $62(5.6 \%)$ & $<0.001$ \\
\hline 21 & I have often found it difficult to limit how much I drink & $92(8.3 \%)$ & $56(5.0 \%)$ & $<0.001$ \\
\hline 20 & $\begin{array}{l}\text { I have neglected my obligations to family, work, or school } \\
\text { because of drinking }\end{array}$ & $86(7.7 \%)$ & $62(5.6 \%)$ & 0.002 \\
\hline 17 & $\begin{array}{l}\text { My drinking has created problems between myself and } \\
\text { my boyfriend/girlfriend/spouse, parents, or other near relatives }\end{array}$ & $79(7.1 \%)$ & $50(4.5 \%)$ & $<0.001$ \\
\hline 14 & I have woken up in an unexpected place after heavy drinking & $76(6.8 \%)$ & $37(3.3 \%)$ & $<0.001$ \\
\hline 8 & My physical appearance has been harmed by my drinking & $68(6.1 \%)$ & $51(4.6 \%)$ & 0.027 \\
\hline 23 & I have become very rude, obnoxious, or insulting after drinking & $66(5.9 \%)$ & $42(3.8 \%)$ & 0.003 \\
\hline 19 & I have driven a car when I knew I had too much to drink to drive safely & $55(5.0 \%)$ & $31(2.8 \%)$ & 0.002 \\
\hline 18 & I have felt like I needed a drink after l'd got up (that is, before breakfast) & $26(2.3 \%)$ & $26(2.3 \%)$ & 1.000 \\
\hline 22 & I have passed out from drinking & $21(1.9 \%)$ & $26(2.3 \%)$ & 0.473 \\
\hline & Total BYAACQ score mean (SD) & $4.9(3.8)$ & $2.6(3.5)$ & $<0.001$ \\
\hline$*$ & $\begin{array}{l}\text { I have physically injured myself or others after drinking - } \\
\text { separate to being in a fight }\end{array}$ & $112(10.1 \%)$ & $61(5.5 \%)$ & $<0.001$ \\
\hline$*$ & I have got into a fight after drinking & $46(4.1 \%)$ & $45(4.1 \%)$ & 1.000 \\
\hline
\end{tabular}

Notes: The percentage "yes" on a particular item is shown. *Additional question, added by the authors.

Abbreviations: AMED, alcohol mixed with energy drinks; BYAACQ, Brief Young Adult Alcohol Consequences Questionnaire; SD, standard deviation.

The data clearly show that alcohol consumption exceeds levels of consumption that are generally accepted as safe, and the majority of students engaged in binge drinking, especially on days when they did not consume AMED (see Table 2).

Therefore, there is still a lot of work to do in preventing excessive alcohol consumption amongst Dutch students. From our data, it is apparent that focusing specifically on AMED consumption is not warranted. The significance of the study results lies in the fact that this is the first large-scale survey using appropriate methodology (ie, a within-subject design) to determine whether mixing alcohol with energy drinks has an effect on overall alcohol consumption when compared with consuming alcohol only. This information cannot be obtained reliably from between-group comparisons. It can be argued that recall bias may interfere with obtaining reliable survey data. However, when applying a within-subject design, there is no reason to assume that participants will recall consumption characteristics differently between AMED or alcohol-only occasions. To avoid the possibility of recall bias entirely, a prospective study design may be a solution, 
but it would be expensive and time-consuming to achieve a sample size as large as that in the current survey.

Interestingly, when applying a between-groups design, as used by other researchers to compare alcohol-only and AMED groups for demographics and alcohol-only consumption patterns, the groups differed from each other on variables concerning alcohol-only consumption and its consequences, drug use and smoking, following a standard pattern of AMED > alcohol only. This observed pattern could be caused by underlying personality characteristics that might differ between the groups, for instance levels of risk-taking behavior. The same authors that claim increased alcohol consumption caused by energy drinks based on such a between-groups design also report that AMED consumers have higher scores on (impulsive) sensation-seeking and childhood conduct problems. ${ }^{11,12}$ Moreover, having a sportsrelated identity is associated with frequency of energy drink consumption, mediated by masculine norms and level of risk-taking behavior. ${ }^{11,12,26}$ Increased levels of risk-taking behavior may be reflected by a generally disinhibited behavioral pattern for an individual. The findings of the current study and others ${ }^{11,12,26}$ confirm that individuals who consume more alcohol also use more drugs. ${ }^{27}$ Taken together the focus of research should not be on AMED consumption but on persons who are involved in heavy alcohol consumption per se. Future research is needed to explore the possibility that this specific group of alcohol consumers have different personality characteristics, ie, higher risk-taking, underlying their pattern of increased substance use.

The reduction in alcohol consumption reported for the AMED group when mixing alcohol with energy drinks as compared with drinking alcohol only was not expected. It was hypothesized that there would be no difference and we have no clear explanation for this observed decrease in alcohol consumption. When looking at the ingredients of energy drinks, it could be speculated that taurine (a nonessential amino acid and an ingredient of most energy drinks) may have an effect on alcohol consumption, given that a modest reduction of voluntary ethanol consumption induced by taurine has been found in rats. ${ }^{28}$ Other ingredients in energy drinks are unlikely to play a role. However, the low intraclass correlations with a maximum of 0.6 suggest interindividual differences, indicating that factors other than coconsumption of energy drinks may explain the observed decrease in alcohol consumption. A possible reason for decreased overall alcohol consumption may be that spirits and energy drinks are generally more expensive than beer and wine. Wagenaar et al showed that the price of alcohol beverages is inversely related to the quantity of alcohol consumed. ${ }^{29}$ However, it is unknown if and how much students had to pay for their alcoholic and energy drinks on the occasions they reported in our survey, or whether they were consumed at home or in a bar.

Our data show that the maximum number of drinks consumed when drinking alcohol only (10.7) was much higher than last month's maximum number of alcoholic drinks on AMED occasions (4.5). In fact, the maximum number of alcoholic drinks on AMED occasions equals that of the 4-5 rule, whereas this is doubled for the maximum monthly consumption of alcohol only (when not mixing). Therefore, it is understandable that negative consequences are experienced more commonly when people do not mix alcohol with energy drinks. It is likely that alcohol-related consequences occur most often on heavy drinking days and less often on days during which few alcoholic drinks are consumed. Although we have information on the number of drinking days, it would not be correct to use this information as a covariate in statistical analysis. The main reason for this is that it is unknown how many of the total drinking days were heavy drinking days (ie, close to the maximum monthly number of drinks) and how many were "normal" drinking days (ie, without experiencing negative consequences). Although there are data on the number of days spent intoxicated and the number of days on which more than 4-5 alcoholic drinks were consumed, including these values in the statistical analysis would result in speculative interpretation of the data, because it can only be guessed if and how many negative consequences subjects experienced on each of these days. The most firm conclusion supported by our data is that people consume less alcohol when they mix alcohol with energy drinks, both on average drinking days and on their maximum heavy drinking occasions. It is understandable that fewer negative consequences are experienced when alcohol consumption is reduced by mixing it with energy drinks.

Our analysis shows that the student sample obtained does not differ significantly from the total Utrecht student population. ${ }^{25}$ Also, there is no reason to assume that students from Utrecht University are very different from those attending other universities in The Netherlands. Nevertheless, a limitation of this survey is that it was conducted only in The Netherlands, which may limit the generalizability of its results to other countries. Therefore, this study will be replicated in other parts of the world, including Australia and the US. These surveys will also adopt a within-subject design and include a sufficient number of participants in the AMED group to ensure adequate statistical power in order to 
have confidence in the results. Furthermore, any underlying personality characteristics likely to cause differences in alcohol-only consumption per se need to be examined in greater detail. In conclusion, the results of this survey show that mixing alcohol with energy drinks decreases overall alcohol consumption, and decreases the likelihood of experiencing negative alcohol-related consequences.

\section{Disclosure}

This survey was supported by a grant from Red Bull GmbH. Red Bull GmbH was not involved in the design and conduct of the study, collection, management, analysis, interpretation of the data, or preparation of the manuscript. JV has received research support from Takeda Pharmaceuticals and Red Bull $\mathrm{GmbH}$, and has been a scientific advisor for Takeda, SanofiAventis, Transcept, Sepracor, Red Bull GmbH, Deenox, Trimbos Institute, and CBD. BO is a scientific advisor for Emotional Brain BV and has received research support from Emotional Brain, PsychoGenics Inc, Sepracor, Servier, Abbott, and the Dutch Brain Research Organization. The other authors have no potential conflicts of interest to disclose.

\section{References}

1. Hasin DS, Stinson FS, Ogburn E, Grant BF. Prevalence, correlates, disability, and comorbidity of DSM-IV alcohol abuse and dependence in the United States: results from the National Epidemiologic Survey on Alcohol and Related Conditions. Arch Gen Psychiatry. 2007;64:830-842.

2. Mokdad AH, Marks JS, Stroup DF, Gerberding JL. Actual causes of death in the United States, 2000. JAMA. 2004;291:1238-1245.

3. Young-Wolff KC, Enoch MA, Prescott CA. The influence of geneenvironment interactions on alcohol consumption and alcohol use disorders: a comprehensive review. Clin Psychol Rev. 2011;31:800-816.

4. World Health Organization. Global Status Report on Alcohol and Health. Geneva, Switzerland: World Health Organization; 2011.

5. McCambridge J, McAlaney J, Rowe R. Adult consequences of late adolescent alcohol consumption: a systematic review of cohort studies. PLoS Med. 2011;8:e1000413.

6. Hingson RW, Zha W, Weitzman ER. Magnitude of and trends in alcoholrelated mortality and morbidity among US college students ages18-24, 1998-2005. J Stud Alcohol Drugs. 2009; Suppl 16:12-20.

7. Spear LP. Adolescent neurobehavioral characteristics, alcohol sensitivities, and intake: setting the stage for alcohol use disorders? Child Dev Perspect. 2011;5:231-238.

8. Verster JC, Aufricht C, Alford C. Energy drinks mixed with alcohol: misconceptions, myths, and facts. Int J Gen Med. 2012;5:187-198.

9. Reissig CJ, Strain EC, Griffiths RR. Caffeinated energy drinks a growing problem. Drug Alcohol Depend. 2009;99:1-10.
10. O'Brien MC, McCoy TP, Rhodes SD, Wagoner A, Wolfson M. Caffeinated cocktails: energy drink consumption, high-risk drinking, and alcohol-related consequences among college students. Acad Emerg Med. 2008;15:453-460.

11. Arria AM, Caldeira KM, Kasperski SJ, et al. Increased alcohol consumption, nonmedical prescription drug use, and illicit drug use are associated with energy drink consumption among college students. J Addict Med. 2010;4:74-80.

12. Arria AM, Caldeira KM, Kasperski SJ, Vincent KB, Griffiths RR, O'Grady KE. Energy drink consumption and increased risk for alcohol dependence. Alcohol Clin Exp Res. 2011;35:365-375.

13. Miller KE. Energy drinks, race, and problem behaviors among college students. J Adolesc Health. 2008;43:490-497.

14. Thombs DL, O’Mara RJ, Tsukamoto M, et al. Event-level analyses of energy drink consumption and alcohol intoxication in bar patrons. Addict Behav. 2010;35:325-330.

15. Berger LK, Fendrich M, Chen HY, Arria AM, Cisler RA. Sociodemographic correlates of energy drink consumption with and without alcohol: results of a community survey. Addict Behav. 2010;36:516-519.

16. Verster JC, Alford C. Unjustified concerns about energy drinks. Curr Drug Abuse Rev. 2011;4:1-3.

17. Skeen MP, Glenn LL. Imaginary link between alcoholism and energy drinks. Alcohol Clin Exp Res. 2011;35:1375-1376.

18. Penning R, de Haan L, Verster JC. Caffeinated drinks, alcohol consumption, and hangover severity. Open Neuropsychopharmacol J. 2011;4:36-39.

19. Rossheim ME, Thombs DL. Artificial sweeteners, caffeine, and alcohol intoxication in bar patrons. Alcohol Clin Exp Res. 2011;35:1891-1896.

20. Woolsey C, Waigandt A, Beck NC. Athletes and energy drinks: reported risk-taking and consequences from the combined use of alcohol and energy drinks. J Appl Sport Psychol. 2010;22:65-71.

21. Price SR, Hilchey CA, Darredeau C, Fulton HG, Barrett SP. Energy drink co-administration is associated with increased reported alcohol ingestion. Drug Alcohol Rev. 2010;29:331-333.

22. Roy M, Dum M, Sobell LC, et al. Comparison of the quick drinking screen and the alcohol timeline followback with outpatient alcohol abusers. Subst Use Misuse. 2008;43:2116-2123.

23. Sobell LC, Agrawal S, Sobell MB, et al. Comparison of a quick drinking screen with the timeline followback for individuals with alcohol problems. J Stud Alcohol Drugs. 2003;64:858-861.

24. Verster JC, Herwijnen J, Olivier B, Kahler CW. Validation of the Dutch version of the Brief Young Adult Alcohol Consequences Questionnaire (B-YAACQ). Addict Behav. 2009;34:411-414.

25. de Haan L, de Haan H, Olivier B, Verster J. Alcohol mixed with energy drinks: methodology and design of the Utrecht Student Survey. Int J Gen Med. 2012;5:889-898.

26. Miller KE. Wired: energy drinks, jock identity, masculine norms, and risk taking. J Am Coll Health. 2008;56:481-490.

27. de Haan L, Kuipers E, Kuerten Y, van Laar M, Olivier B, Verster JC. The RT-18: a new screening tool to assess young adult risk-taking behavior. Int J Gen Med. 2011;4:575-584.

28. Olive M. Interactions between taurine and ethanol in the central nervous system. Amino Acids. 2002;23:345-357.

29. Wagenaar AC, Salois MJ, Komro KA. Effects of beverage alcohol price and tax levels on drinking: a meta-analysis of 1003 estimates from 112 studies. Addiction. 2009;104:179-190.
International Journal of General Medicine

\section{Publish your work in this journal}

The International Journal of General Medicine is an international, peer-reviewed open-access journal that focuses on general and internal medicine, pathogenesis, epidemiology, diagnosis, monitoring and treatment protocols. The journal is characterized by the rapid reporting of reviews, original research and clinical studies across all disease areas.

\section{Dovepress}

A key focus is the elucidation of disease processes and management protocols resulting in improved outcomes for the patient.The manuscript management system is completely online and includes a very quick and fair peer-review system. Visit http://www.dovepress.com/ testimonials.php to read real quotes from published authors. 